Article

\title{
The Biosynthesis of Phenolic Compounds Is an Integrated Defence Mechanism to Prevent Ozone Injury in Salvia officinalis
}

\author{
Alessandra Marchica ${ }^{1}$, Lorenzo Cotrozzi ${ }^{1}{ }^{\circledR}$, Rebecca Detti ${ }^{1}$, Giacomo Lorenzini ${ }^{1,2,3}$,

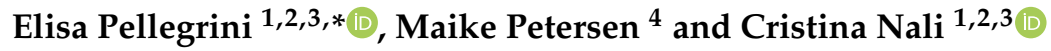 \\ 1 Department of Agriculture, Food and Environment, University of Pisa, Via del Borghetto 80, \\ I-56124 Pisa, Italy; alessandra.marchica@agr.unipi.it (A.M.); lorenzo.cotrozzi@agr.unipi.it (L.C.); \\ rebeccadetti@gmail.com (R.D.); giacomo.lorenzini@unipi.it (G.L.); cristina.nali@unipi.it (C.N.) \\ 2 CIRSEC, Centre for Climate Change Impact, University of Pisa, Via del Borghetto 80, I-56124 Pisa, Italy \\ 3 Nutrafood Research Center, University of Pisa, Via del Borghetto 80, I-56124 Pisa, Italy \\ 4 Institut für Pharmazeutische Biologie und Biotechnologie, Philipps-Universität Marburg, Robert Koch Str. 4, \\ D-35037 Frankfurt, Germany; petersen@staff.uni-marburg.de \\ * Correspondence: elisa.pellegrini@unipi.it
}

Received: 9 November 2020; Accepted: 11 December 2020; Published: 14 December 2020

\begin{abstract}
Specialized metabolites constitute a major antioxidant system involved in plant defence against environmental constraints, such as tropospheric ozone $\left(\mathrm{O}_{3}\right)$. The objective of this experiment was to give a thorough description of the effects of an $\mathrm{O}_{3}$ pulse $(120 \mathrm{ppb}, 5 \mathrm{~h})$ on the phenylpropanoid metabolism of sage, at both biochemical and molecular levels. Variable $\mathrm{O}_{3}$-induced changes were observed over time among the detected phenylpropanoid compounds (mostly identified as phenolic acids and flavonoids), likely because of their extraordinary functional diversity. Furthermore, decreases in the phenylalanine ammonia-lyase (PAL), phenol oxidase (PPO), and rosmarinic acid synthase (RAS) activities were reported during the first hours of treatment, probably due to an $\mathrm{O}_{3}$-induced oxidative damage to proteins. Both PAL and PPO activities were also suppressed at $24 \mathrm{~h}$ from the beginning of exposure, whereas enhanced RAS activity occurred at the end of treatment and at the recovery time, suggesting that specific branches of the phenolic pathways were activated. The increased RAS activity was accompanied by the up-regulation of the transcript levels of genes like $R A S$, tyrosine aminotransferase, and cinnamic acid 4-hydroxylase. In conclusion, sage faced the $\mathrm{O}_{3}$ pulse by regulating the activation of the phenolic biosynthetic route as an integrated defence mechanism.
\end{abstract}

Keywords: antioxidants; caffeic acid; flavonoids; hydroxybenzoic acids; hydroxycinnamic acids; PAL; phenylpropanoids; rosmarinic acid; sage; secondary metabolites

\section{Introduction}

Plants, being sessile organisms, are persistently exposed to environmental stresses, which usually have negative impacts on their growth and productivity [1]. Therefore, plants have developed various adaptation mechanisms that can be activated to sustain their life cycle under environmental challenges [2]. Plants possess a forceful and multifarious antioxidant system composed of enzymatic reactions (e.g., superoxide dismutase, catalase, ascorbate peroxidase) and non-enzymatic compounds (e.g., ascorbic acid and glutathione), which are involved in detoxification, removal, and/or neutralization of reactive oxygen species (ROS) overproduction due to biotic and abiotic stresses [3].

Secondary metabolites-classified into, e.g., terpenoids, phenylpropanoids, and nitrogen containing compounds, based on their biosynthetic origin [4]-are well suited to constitute a major antioxidant system with a central role in plant defence against environmental constraints 
by (i) avoiding the generation of ROS (e.g., catalyzing oxygenation reactions through formation of metallic complexes reducing/inhibiting the activities of oxidizing enzymes), and (ii) quenching ROS once they are formed [5]. These specialized molecules are produced by plants to respond to a large number of diverse signals, both internal ones and those emanating from the environment, which are critical for their survival and adaption as sessile organisms. Accumulation of these compounds is usually a consistent feature in the plant defence mechanisms as they can increase the tolerance and adaptability to different stresses [5].

Phenolics are the largest group of plant secondary metabolites. Varying from simpler aromatic compounds to more complex ones, they mainly derive from the shikimate/phenylpropanoid pathway [6]. They are classified as hydroxybenzoic and hydroxycinnamic acid derivatives based on their distinctive carbon frameworks as well as on the position and number of hydroxyl groups on the aromatic ring [7]. Hydroxycinnamic acids, which are derivatives of cinnamic acid having a C6-C3 framework, are more prevalent in nature than hydroxybenzoic acids, which instead are derivatives of benzoic acid with a C6-C1 structure. Hydroxycinnamic acids are also more efficacious antioxidants than hydroxybenzoic acids because of the presence in their structure of the $-\mathrm{CH}=\mathrm{CH}-\mathrm{COOH}$ group, instead of the $-\mathrm{COOH}$ group [8]. The accumulation of phenolics in plant tissues can be reached in two ways: (i) reducing their consumption because the oxidative pressure is low, and/or (ii) enhancing their biosynthetic route in an integrated defence mechanism through increased performance of enzymes, such as phenylalanine ammonia-lyase (PAL) and chalcone synthase (CHS), accompanied by the up-regulation of the transcript levels of genes encoding key biosynthetic enzymes like PAL, cinnamic acid 4-hydroxylase $(\mathrm{C} 4 \mathrm{H})$, 4-coumarate CoA-ligase (4CL), tyrosine aminotransferase (TAT), and rosmarinic acid synthase (RAS) (Figure $1[4,9])$.

Salvia (sage), the largest genus of the Lamiaceae family, broadly cultivated in the Mediterranean basin, is a rich source of phenylpropanoids [10]. Caffeic acid derivatives play a major role among the specialized metabolites of sage species [11]. Moreover, flavonoids are widely distributed in this genus, mostly present as flavones (e.g., apigenin, luteolin, and their corresponding 6-hydroxylated derivatives), flavonols, and their glycosides (e.g., kaempferol and quercetin) [11]. Flavonoids are known to play a major role in reducing photo-oxidative damage [12] and scavenging ROS [13].

In the context of climate change, the phenylpropanoid pathway is one of the most affected targets of detrimental environment conditions, such as increasing amounts of tropospheric ozone $\left(\mathrm{O}_{3}\right)$, which affect not only the synthesis, but also the accumulation of these metabolites and the induction of related enzymes and genes. Tropospheric $\mathrm{O}_{3}$ is one of the most important greenhouse gases involved in global warming, harmful to human health and crop production because of its high oxidative potential [14]. Despite numerous legislatory attempts aimed to control emissions of its precursors, $\mathrm{O}_{3}$ is still among the major air pollutants worldwide, especially in areas with elevated temperatures such as the Mediterranean basin, where it frequently exceeds the World Health Organization (WHO) guideline average values of $50 \mathrm{ppb}$ [15]. For example, it reached hourly peaks of $90 \mathrm{ppb}$ during the summer 2019 in Italy [16]. In a previous study [17], our research group demonstrated that $S$. officinalis plants under chronic $\mathrm{O}_{3}$ exposure ( $120 \mathrm{ppb}, 5 \mathrm{~h} \mathrm{day}^{-1}$, for 90 days) were able to activate already after one month of exposure a photoprotection mechanism including carotenoids and phenylpropanoid compounds (even though impairments to plant processes occurred). Although it is known that plant responses to chronic and acute $\mathrm{O}_{3}$ may differ [18], to the best of our knowledge, the effects of a single $\mathrm{O}_{3}$ pulse on $\mathrm{S}$. officinalis have not been investigated, except by Marchica et al. [19], using a very high $\mathrm{O}_{3}$ concentration (i.e., $200 \mathrm{ppb}$ ).

For these reasons, the primary objective of the present experiment was to give a thorough description of the effects of an $\mathrm{O}_{3}$ pulse at a lower concentration $(120 \mathrm{ppb})$ on the phenylpropanoid metabolism of $S$. officinalis at both biochemical and molecular levels, also focusing on the expression of genes and on enzyme activities related to the biosynthesis of rosmarinic acid. Specifically, we asked the following questions: (i) What is the potential role of phenolics (e.g., caffeic acid derivatives) and flavonoids in regulating the responses to a single $\mathrm{O}_{3}$ pulse? (ii) Which enzymes involved in the 
phenolic pathway are more affected by high $\mathrm{O}_{3}$ levels, and why? (iii) Which molecular alterations of gene expression related to the biosynthesis of rosmarinic acid are induced by $\mathrm{O}_{3}$ treatment?

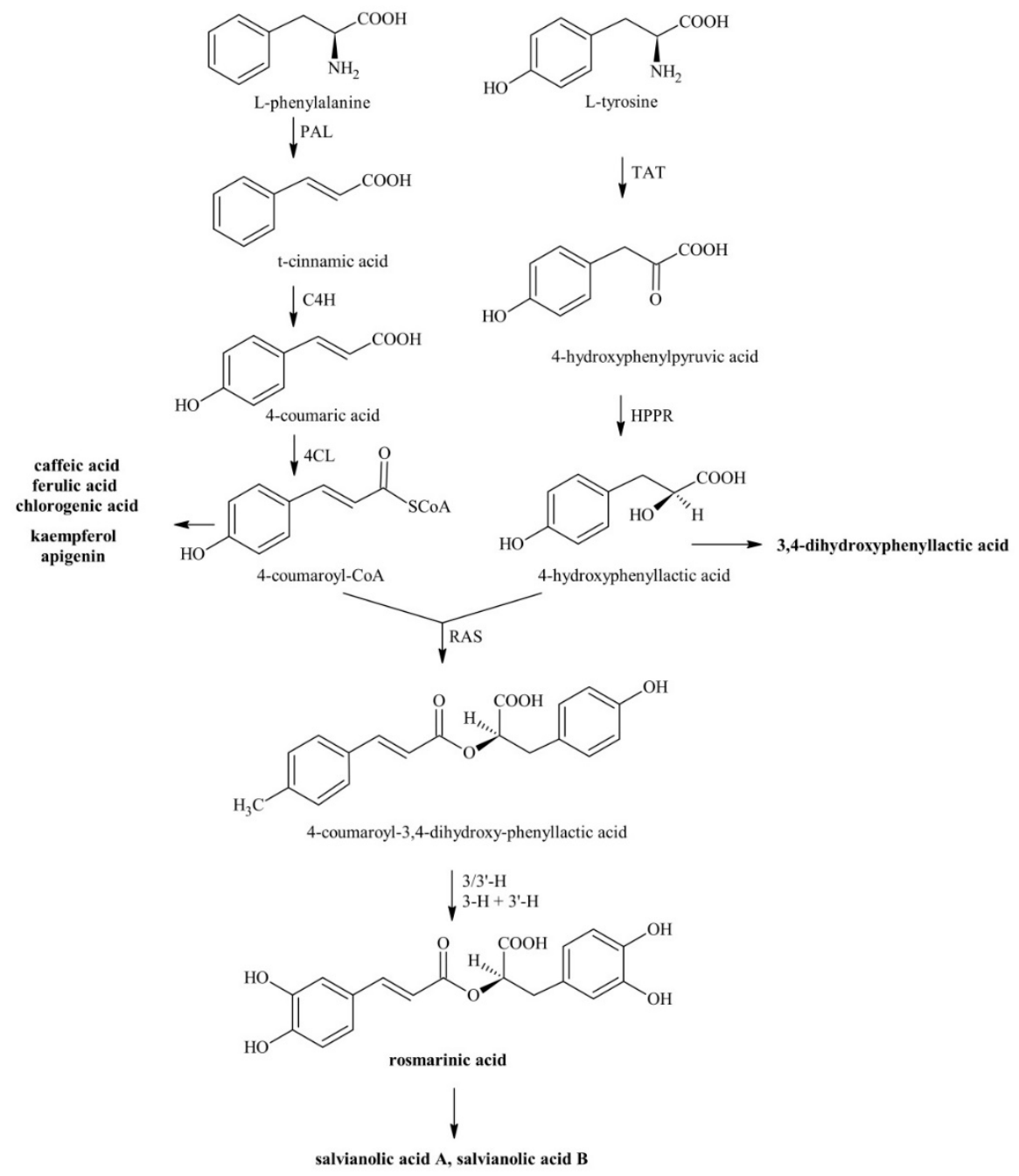

Figure 1. Intermediates and enzymes of the biosynthesis of rosmarinic acid and related phenolic compounds; $\mathrm{PAL}=$ phenylalanine ammonia-lyase, $\mathrm{C} 4 \mathrm{H}=$ cinnamic acid 4-hydroxylase, $4 \mathrm{CL}=4$-coumarate CoA-ligase, $\mathrm{TAT}=$ tyrosine aminotransferase, $\mathrm{HPPR}=$ hydroxyphenylpyruvate reductase, $\mathrm{RAS}=$ rosmarinic acid synthase, 3-H, 3'-H, 3/3'-H = 3-/3'-hydroxylases.

\section{Materials and Methods}

\subsection{Experimental Design}

Experimental activities were performed at the field-station of San Piero a Grado (Pisa, Italy; $43^{\circ} 40^{\prime} 48^{\prime \prime} \mathrm{N}, 10^{\circ} 20^{\prime} 48^{\prime \prime}$ E, $2 \mathrm{~m}$ a.s.l.) owned by the Department of Agriculture, Food, and Environment of the University of Pisa. In May 2019, 30 seedlings of S. officinalis (8 months old, 1-3 stems per seedling), grown under field conditions in plastic pots (3.7 L volume) containing a mixture of peat and steam-sterilized soil $(1: 1, v / v)$, were selected for uniformity of size (approximately $30 \mathrm{~cm}$ tall), distributed among four chambers placed inside a greenhouse (day and night mean temperatures were 28 and $20^{\circ} \mathrm{C}$, respectively, and maximum day and night relative humidity were approximately 60 and $50 \%$, respectively) under charcoal-filtered air. After ten days, half of the plants were exposed to a target $\mathrm{O}_{3}$ concentration of $120 \mathrm{ppb}\left(1 \mathrm{ppb}=1.96 \mu \mathrm{g} \mathrm{m}{ }^{-3}\right.$, at $25^{\circ} \mathrm{C}$ and $\left.101.325 \mathrm{kPa}\right)$ for $5 \mathrm{~h}$ from 10:00 to 15:00, while the other half of the plants were maintained under charcoal-filtered air containing negligible $\mathrm{O}_{3}$ concentrations (controls). Ozone was generated by a Fisher 500 air-cooled 
apparatus (Fisher America Inc., Houston, TX, USA), supplied with pure oxygen, and mixed with inlet air entering the fumigation chamber; its concentration was continuously measured inside the chambers at plant height with a Serinus 10 analyzer (Ecotech Acoem Group, Milan, Italy), as described by Marchica et al. [19]. At 0, 1, 2, 5, and $24 \mathrm{~h}$ from the beginning of exposure (FBE), the three youngest fully expanded leaves per plant were harvested on three plants per treatment per sampling time, flash frozen in liquid nitrogen, ground, and stored at $-80^{\circ} \mathrm{C}$ until biochemical and molecular analyses.

\subsection{Biochemical Analyses}

\subsubsection{Metabolites Involved in the Phenylpropanoid Pathway}

Phenylpropanoids were analyzed by ultra-high pressure liquid chromatography (UHPLC) using a UHPLC Dionex UltiMate 3000 system equipped with an Acclaim 120 C18 column (5 $\mu \mathrm{m}$ particle size, $4.6 \mathrm{~mm}$ internal diameter $\times 150 \mathrm{~mm}$ length) mounted in a Dionex TCC-100 column oven, and a Dionex UVD 170U UV-Vis detector (Thermo Scientific, Waltham, MA, USA). Around $45 \mathrm{mg}$ (fresh weight, FW) of leaf material was extracted in $1 \mathrm{~mL}$ of $70 \%$ HPLC-grade methanol for three times, with the third extraction performed after an overnight incubation at $4{ }^{\circ} \mathrm{C}$. At each of the three times, extracts were centrifuged for $20 \mathrm{~min}$ at $16,000 \times \mathrm{g}$ at $20^{\circ} \mathrm{C}$, and supernatants were collected and combined [20]. Then, the mixed supernatants were washed with hexane and filtered through $0.2 \mu \mathrm{m}$ Minisart ${ }^{\circledR}$ SRT 15 aseptic filters. Setting the column oven at $30{ }^{\circ} \mathrm{C}$ and the flow rate at $1 \mathrm{~mL} \mathrm{~min}{ }^{-1}$, phenylpropanoids were eluted as follows: 100\% solvent A (water/methanol/acetic acid, 75:20:5 (v/v/v) for $1 \mathrm{~min}$, a $30 \mathrm{~min}$ linear gradient to $100 \%$ solvent $B$ (water/methanol/acetic acid, 50:45:5, $(v / v / v)$, a $5 \mathrm{~min}$ linear gradient to $100 \%$ solvent A, and finally $5 \mathrm{~min} 100 \%$ solvent A. Phenolic compounds were detected at 250,280, and $350 \mathrm{~nm}$ [21]. Compound concentrations were quantified using equations developed linearly relating peak areas with known amounts of pure standards injected into the UHPLC system. Chromatographic data were processed and recorded by Chromeleon Chromatography Management System software, version 6.60-2004 (Thermo Scientific).

\subsubsection{Enzymes Involved in Phenolic Metabolism}

For protein extraction, leaf material ( $50 \mathrm{mg} \mathrm{FW})$ was ground to powder in liquid nitrogen and added to $6 \mathrm{mg}$ Polyclar 10 and $1.2 \mathrm{~mL} 0.5 \mathrm{M}$ Tris- $\mathrm{HCl}$ buffer ( $\mathrm{pH}$ 10.0) containing $5 \mathrm{mM}$ dithiothreitol and mixed thoroughly. After centrifugation $\left(10,000 \times \mathrm{g}\right.$ for $20 \mathrm{~min}$ at $\left.4{ }^{\circ} \mathrm{C}\right)$, the protein extract was passed through a PD-10 column (GE Healthcare, Chicago, IL, USA) and kept on ice.

Phenylalanine ammonia-lyase (PAL, EC 4.3.1.24) activity was determined by separation and quantification of the formed reaction product $t$-cinnamic acid by HPLC (Hitachi, Merck, Darmstadt, Germany) and photometric detection at $290 \mathrm{~nm}$ according to Döring et al. [9]. The PAL assay consisted of $100 \mu \mathrm{L}$ boric acid/borate buffer $\left(0.078 \mathrm{M} \mathrm{H}_{3} \mathrm{BO}_{3}, 0.03 \mathrm{M} \mathrm{Na}_{2} \mathrm{~B}_{4} \mathrm{O}_{7}\right.$, and $\left.0.02 \mathrm{M} \mathrm{NaCl}\right) \mathrm{pH} 8.8$, $50 \mu \mathrm{L} 0.1 \mathrm{M}$ L-phenylalanine dissolved in the same buffer, and $100 \mu \mathrm{L}$ protein extract (see above). After incubation for $30 \mathrm{~min}$ at $50{ }^{\circ} \mathrm{C}$, the reaction was stopped by adding $50 \mu \mathrm{L} 6 \mathrm{~N} \mathrm{HCl}$. Reaction products were extracted twice by mixing with $500 \mu \mathrm{L}$ ethyl acetate, centrifugation at $16,000 \times g$ for $5 \mathrm{~min}$, and collection of the organic phases. After evaporating the solvent, residues were dissolved in $100 \mu \mathrm{L} 50 \%$ methanol $/ 0.01 \% \mathrm{H}_{3} \mathrm{PO}_{4}$.

Polyphenol oxidase (PPO, EC 1.10.3.2) activity was determined by HPLC (as elaborated below) with photometric detection at $333 \mathrm{~nm}$, according to Leuschner [22]. This assay consisted of $445 \mu \mathrm{L}$ $0.1 \mathrm{M}$ Na-acetate buffer ( $\mathrm{pH} 4.5), 30 \mu \mathrm{L} 1 \mathrm{M}$ ascorbic acid/sodium ascorbate (pH 4.5), $10 \mu \mathrm{L} 10 \mathrm{mM}$ 4-coumaric acid, and $15 \mu \mathrm{L}$ protein extract. After incubation for $10 \mathrm{~min}$ at $30^{\circ} \mathrm{C}$, the reaction was stopped by adding $50 \mu \mathrm{L} 6 \mathrm{~N} \mathrm{HCl}$. Reaction products were extracted as reported above.

Rosmarinic acid synthase (RAS, EC 2.3.1.140) activity was determined by separation and quantification of the hydroxycinnamic acid esters by HPLC (as elaborated below) with photometric detection at $333 \mathrm{~nm}$, according to Berger et al. [23]. This assay consisted of $75 \mu \mathrm{L} 0.1 \mathrm{M}$ potassium phosphate buffer (pH 7.0), $10 \mu \mathrm{L} 12.5 \mathrm{mM}$ ascorbic acid, $10 \mu \mathrm{L} 2.5 \mathrm{mM}$ caffeoyl-CoA, $10 \mu \mathrm{L} 10 \mathrm{mM}$ 
4-hydroxyphenyllactate (pHPL, in $20 \%$ ethanol), and $20 \mu \mathrm{L}$ protein extract. After incubation for $2 \mathrm{~h}$ at $30{ }^{\circ} \mathrm{C}$, the reaction was stopped by adding $20 \mu \mathrm{L} 6 \mathrm{~N} \mathrm{HCl}$. The extraction of the hydroxycinnamic acid esters was performed with ethyl acetate as described above and the dry samples were dissolved in $100 \mu \mathrm{L} 50 \%$ methanol $/ 0.01 \% \mathrm{H}_{3} \mathrm{PO}_{4}$.

Isocratic HPLC analysis of the extracted reaction products of the PAL, PPO, and RAS enzyme activity assays was performed using an Equisil ODS (250 mm length, $4 \mathrm{~mm}$ diameter with a $20 \mathrm{~mm}$ pre-column; Dr. Maisch GmbH, Ammerbuch, Germany). The eluents consisted of 50, 40, and 50\% methanol $/ 0.01 \% \mathrm{H}_{3} \mathrm{PO}_{4}$, respectively, eluted at a flow rate of $1 \mathrm{~mL} \mathrm{~min}^{-1}$. $t$-Cinnamic acid was detected at $290 \mathrm{~nm}$, and caffeic acid and hydroxycinnamic acid esters at $333 \mathrm{~nm}$.

\subsection{Molecular Analyses}

\subsection{1. qRT-PCR Primer Design}

Specific primers for sage [elongation factor (EF) $1 \alpha$, actin, PAL, C4H, TAT, and RAS] were constructed on homologous sequences selected after BLAST analysis, using as a query Melissa officinalis and Salvia milthiorriza (GenBank acc. No. FN665700, DQ355979, JN863949, FR670523, KM575933, HM231319, and HM051058). After CLUSTALW multiple-sequence alignment, primers were designed using Primer3 software ( $230 \mathrm{bp}$ maximum length, optimal melting temperature at $59.3^{\circ} \mathrm{C}$, GC content between 45 and 60\%; Applied Biosystems, Foster City, CA, USA; Table 1).

Table 1. Primers for housekeeping genes and specific primers for Salvia officinalis.

\begin{tabular}{cc}
\hline Primers & Sequences \\
\hline \multirow{2}{*}{ EF1 $\alpha$} & F: 5'-ACAACCCTGAGAAGATCCC-3' \\
& R: 5'-GCACAGTTCCAATACCACCAAT-3' \\
Actin & F: 5'-TCTCTTGACAGAAGCCCCTCT-3' \\
& R: 5'-GATGGGGACTGTATGGCTGA-3' \\
PAL & F: 5'-GAAGAACACCGTGAGCCAAG-3' \\
& R:5'-GCTCACACTCTTCTCCCCTT-3' \\
C4H & F: 5'-ATCTGAACCACCGCAACCTC-3' \\
& R: 5'-GTGAACACCATGTCCTGACC-3' \\
TAT & F: 5'-GCACCTAAAGAAGATTGCTGAG-3' \\
& R: 5'-ATTGATGACCAACCAACCAAGG-3' \\
RAS & F:5'-ACTACTTGAGGTCGTCGCTC-3' \\
& R:5'-CGGATTTGGCAGGAGATAGC-3' \\
\hline
\end{tabular}

\subsubsection{RNA Extraction and Relative Expression Analyses}

Total RNA was extracted from frozen $\left(-80^{\circ} \mathrm{C}\right)$ leaf tissue using the RNeasy ${ }^{\circledR}$ Mini Plant Kit (Qiagen Benelux B.V., Venlo, The Netherlands) treated with Amplification Grade DNase I (Sigma-Aldrich, St. Louis, MO, USA) and reverse-transcribed into cDNA (400 ng per sample) using the iScript cDNA synthesis kit (BioRad, Hercules, CA, USA) following the manufacturer's instructions. Elongation factor $1 \alpha$ was used as a reference gene after confirmation of its transcriptional stability in our experimental conditions and synthesized by Eurofins MWG Operon (Ebersberg, Germany). Each $12 \mu \mathrm{L}$ qRT-PCR assay contained $5 \mu \mathrm{L}$ cDNA (diluted 1:20), $0.25 \mu \mathrm{L}$ of each primer $(10 \mu \mathrm{M}), 0.5$ $\mu \mathrm{L}$ nuclease-free water, and $7 \mu \mathrm{L}$ PerfeCTa ${ }^{\circledR}$ SYBR Green SuperMix (Quantabio, Beverly, MA, USA), following the manufacturer's instructions. qRT-PCR analyses were performed in a PikoReal 96 (Thermo Fisher). The three-step thermal profile comprised three segments: (1) $95^{\circ} \mathrm{C} / 2 \mathrm{~min}$, (2) 40 cycles of $95^{\circ} \mathrm{C} / 15 \mathrm{~s}, 55^{\circ} \mathrm{C} / 45 \mathrm{~s}, 68^{\circ} \mathrm{C} / 60 \mathrm{~s}$. Three technical replicates were analyzed for each biological sample. The efficiency of each primer was evaluated by linear regression analysis of serial dilutions of cDNA. The expression level of the four target genes was individually normalized to the transcript level of EF1 $\alpha$ and actin, and calculated by the Pfaffl method [24]. 


\subsection{Statistical Analyses}

Three plants per treatment per time were used (the three leaves sampled from each plant were analyzed separately and then averaged to keep the plant as a statistical unit). The normality of data was preliminarily tested by the Shapiro-Wilk test. The effects of $\mathrm{O}_{3}$, time, and their interaction on leaf parameters were analyzed using a full factorial two-way analysis of variance (ANOVA). Comparisons among means were determined by the least significant Tukey's honestly significant difference (HSD) post-hoc test. Effects with $p \leq 0.05$ were considered statistically significant. Statistical analyses were performed in JMP 11 (SAS Institute Inc., Cary, NC, USA).

\section{Results}

\subsection{Metabolites Involved in the Phenylpropanoid Pathway}

A total of 11 phenylpropanoids were identified: nine phenolic acids (hydroxycinnamic acids and derivatives: caffeic acid, ferulic acid, chlorogenic acid, rosmarinic acid, salvianolic acids A and B; hydroxybenzoic acids: gallic and benzoic acids; 3,4-dihydroxyphenyllactic acid (danshensu) as tyrosine derived phenolic acid) (Figure 2) and two of the most common flavonoids (apigenin and kaempferol, Figure 3). Rosmarinic and benzoic acids showed higher contents than the other compounds 0.01-1.73 (min-max; all other compounds) vs. 4.2-11.86 and 1.36-6.07 $\mu \mathrm{mol} \mathrm{g}^{-1} \mathrm{FW}$ (rosmarinic and benzoic acid, respectively). Although no visible symptoms were observed, $\mathrm{O}_{3}$ exposure induced significant changes to the phenylpropanoid profile throughout the whole experiment.

Caffeic acid and ferulic acid levels in ozone-treated leaves started to increase at $2 \mathrm{~h} \mathrm{FBE}(+7$ and $46 \%$, respectively; Figure 2A,C) and maintained increased levels throughout the whole experiment

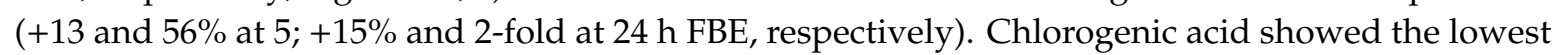
concentration of all observed compounds (Figure 2B) and did not show a clear trend; it significantly decreased at $1 \mathrm{~h} \mathrm{FBE} \mathrm{(-67 \%} \mathrm{in} \mathrm{comparison} \mathrm{with} \mathrm{controls),} \mathrm{was} \mathrm{higher} \mathrm{than} \mathrm{controls} \mathrm{at} 2 \mathrm{~h} \mathrm{FBE}(+43 \%)$, did not show significant differences between treatments at the end of exposure, and significantly decreased again at the recovery time $(-63 \%)$. Under $\mathrm{O}_{3}$ treatment, the levels of $\mathrm{RA}$, salvianolic acid $\mathrm{B}$, and the tyrosine-derived compound 3,4-dihydroxyphenyllactic acid (danshensu) were strongly reduced at $1 \mathrm{~h}$ FBE $(-43,-46$ and $-71 \%$ respectively; Figure 2D,F,I), and remained lower than controls until the end of $\mathrm{O}_{3}$ treatment (only salvianolic acid B did not show significant differences between treatments at the end of exposure), but they were increased at the recovery time (i.e., $24 \mathrm{~h}$ FBE) reaching their maximum values $(+57 \%,+22 \%$ and about threefold higher than controls, respectively). Salvianolic acid $\mathrm{A}$ in treated plants remained at control levels until the end of exposure and then increased at $24 \mathrm{~h}$ FBE (+33\% in comparison with controls; Figure 2E). Among hydroxybenzoic acids, gallic acid revealed no significant differences between treated and untreated plants at 1 and $5 \mathrm{~h} F B E$, but it was higher in treated plants than in controls at 2 and $24 \mathrm{~h}$ FBE (about two- and fourfold, respectively; Figure 2F). Compared with controls, the levels of benzoic acid of treated plants significantly decreased at $1 \mathrm{~h}$ FBE $(-60 \%$, Figure $2 \mathrm{G})$, then peaked at $2 \mathrm{~h} \mathrm{FBE}(+26 \%)$, and decreased again starting from the end of exposure ( -29 and $-27 \%$ at 5 and $24 \mathrm{~h}$, respectively).

Among the flavonoids, apigenin did not show a clear trend; it significantly decreased at $1 \mathrm{~h}$ FBE $(-65 \%$ in comparison with controls, Figure $3 \mathrm{~A})$, increased at $2 \mathrm{~h}$ FBE $(+35 \%)$, and revealed no significant differences between treatments at 5 and $24 \mathrm{~h}$ FBE. Kaempferol significantly decreased at $2 \mathrm{~h}$ FBE (-88\% in comparison with control, Figure 3B) and strongly increased starting from $5 \mathrm{~h}$ FBE $(+30 \%)$, reaching a maximum at the recovery time (about threefold higher than controls). 

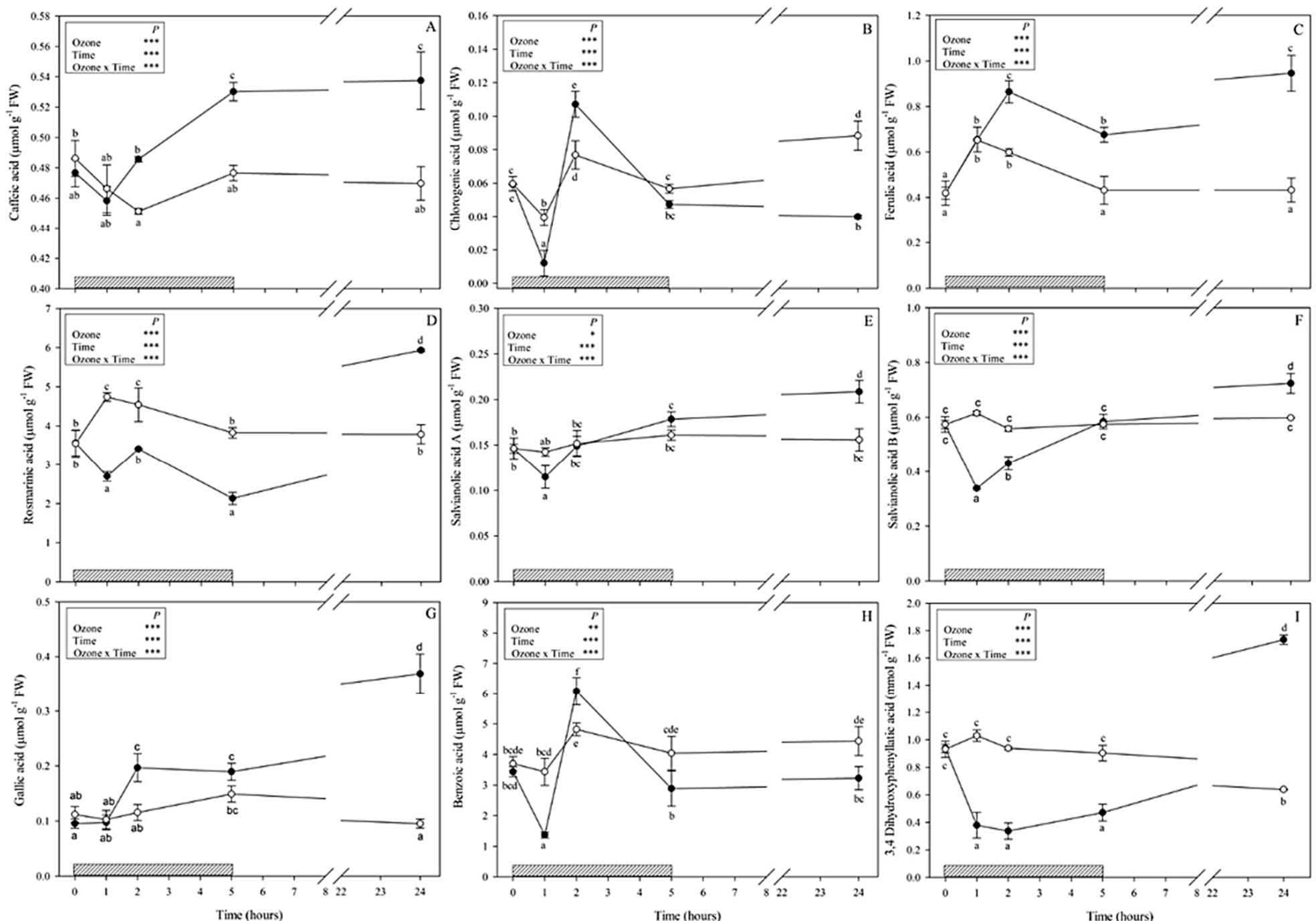

Figure 2. Content of phenolic acids (caffeic acid (A), chlorogenic acid (B), ferulic acid (C), rosmarinic acid (D), salvianolic acid A (E)and salvianolic acid B (F), gallic acid (G), benzoic acid (H), 3,4 dihydroxyphenyllatic acid (I)) $\left(\mu \mathrm{mol} \mathrm{g}^{-1} \mathrm{FW}\right.$ ) in leaves of Salvia officinalis exposed to ozone (120 ppb, $5 \mathrm{~h}$; closed circle) or maintained under 
filtered air (controls; open circle). Measurements were carried out at $0,1,2,5$, and $24 \mathrm{~h}$ from the beginning of exposure. Data are shown as mean \pm standard deviation $(n=3)$. $p$-values show the results of a full factorial two-way analysis of variance (ANOVA) with $\mathrm{O}_{3}$ and time as variability factors ${ }^{* * *} p \leq 0.001 ;{ }^{* *} p \leq 0.01$; ${ }^{*} p \leq 0.05$; ns: $p>0.05)$. For each compound (A-I), different lowercase letters (a-e) indicate significant differences among means, according to the Tukey's HSD post-hoc test $(p \leq 0.05) . \mathrm{FW}=$ fresh weight.
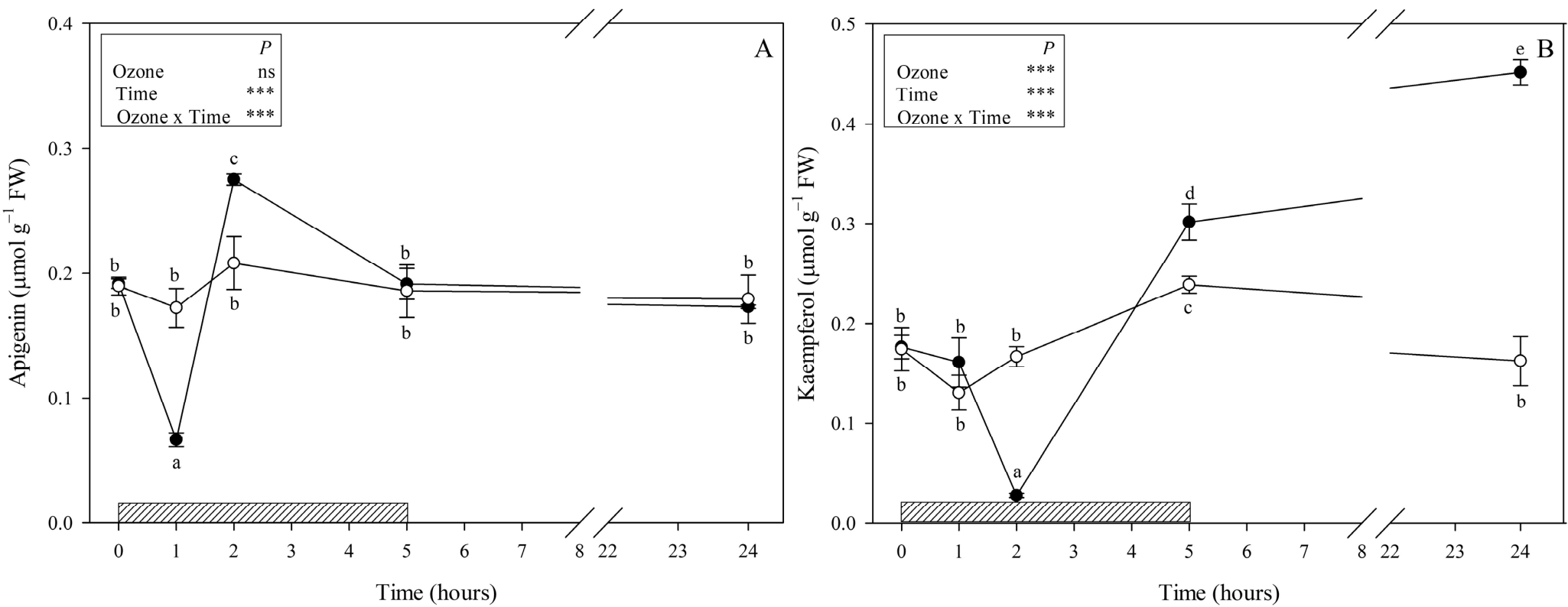

Figure 3. Content of flavonoids (apigenin (A), kaempferol (B)) ( $\mu \mathrm{mol} \mathrm{g}^{-1} \mathrm{FW}$ ) in leaves of Salvia officinalis exposed to ozone (120 ppb, $5 \mathrm{~h}$; closed circle) or maintained under filtered air (controls; open circle). Measurements were carried out at $0,1,2,5$, and $24 \mathrm{~h}$ from the beginning of exposure. Data are shown as mean \pm standard deviation $(n=3)$. $p$-values show the results of a full factorial two-way ANOVA with $\mathrm{O}_{3}$ and time as variability factors (*** $p \leq 0.001$; ns: $p>0.05$ ). For each compound $(\mathbf{A}, \mathbf{B})$, different lowercase letters (a-e) indicate significant differences among means, according to the Tukey's HSD post-hoc test $(p \leq 0.05)$. FW $=$ fresh weight. 


\subsection{Enzymes Involved in the Phenylpropanoid Pathway}

Ozone treatment strongly decreased PAL and PPO activities at 1 and $2 \mathrm{~h}$ FBE (around -50 and $-60 \%$ in comparison with controls, respectively; Figure $4 A, B)$. At the end of the $\mathrm{O}_{3}$ treatment, the activity of these enzymes came back to control levels and decreased again at $24 \mathrm{~h}$ FBE ( -36 and $-47 \%$, respectively). RAS activity slightly decreased at 1 and $2 \mathrm{~h} \mathrm{FBE} \mathrm{(-15} \mathrm{and}-11 \%$ in comparison with control, respectively, Figure $4 \mathrm{C})$ and strongly increased again starting from 5 h FBE $(+23 \%)$, reaching a maximum at the recovery time $(+59 \%)$.

\subsection{Gene Expression Analyses}

At the molecular level, the effect of $\mathrm{O}_{3}$ was investigated by monitoring the transcript abundance of the PAL, C4H, TAT, and RAS genes. In treated plants, a decrease of the transcript levels in comparison with controls was observed at 1 and $2 \mathrm{~h}$ FBE for PAL ( -40 and $-36 \%$, respectively; Figure 5A) and RAS ( -34 and $43 \%$, respectively; Figure 5D), indicating that they were downregulated by $\mathrm{O}_{3}$ or, alternatively, the mRNAs could have been degraded. By contrast, PAL and RAS gene expression was upregulated at the end of treatment (about 2-fold higher than controls), but it decreased again at $24 \mathrm{~h}$ FBE (-22 and $-29 \%$, respectively). Conversely, $\mathrm{C} 4 \mathrm{H}$ and TAT mRNA levels started to increase at $2 \mathrm{~h}$ FBE (about twofold higher than controls; Figure 5B,C) and maintained increased levels throughout the whole period of the experiment, reaching their maximum at $24 \mathrm{~h}$ FBE (16- and 9-fold higher than controls, respectively). 

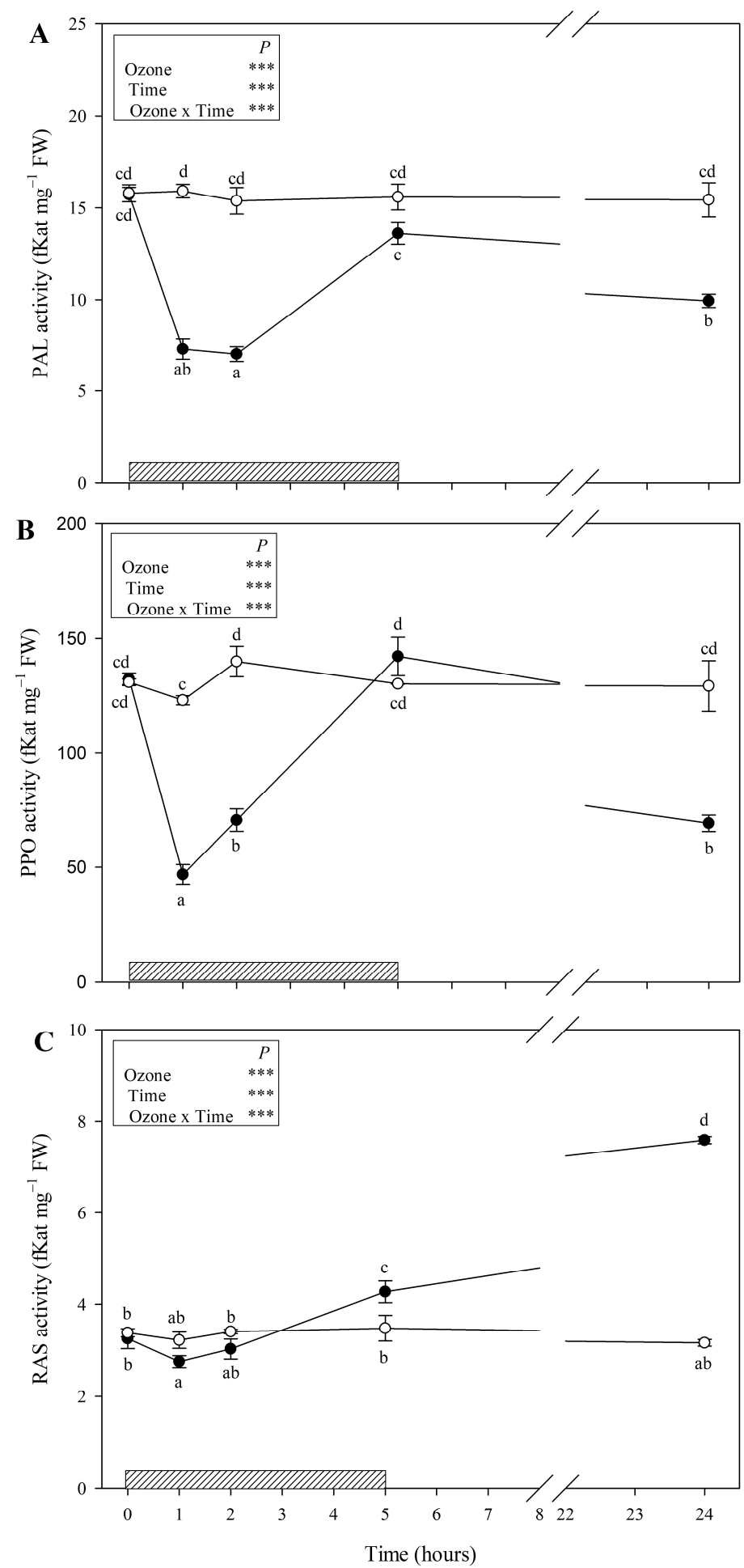

Figure 4. Time course of phenylalanine ammonia-lyase (PAL; (A)), polyphenol oxidase (PPO; (B)), and rosmarinic acid synthase (RAS; (C)) activities in leaves of Salvia officinalis exposed to ozone (120 ppb, 5 h; closed circle) or maintained under filtered air (controls; open circle). Data are shown as mean \pm standard deviation $(n=3)$. Measurements were carried out at $0,1,2,5$, and $24 \mathrm{~h}$ from the beginning of exposure. Boxes show the results of a full factorial two-way ANOVA with ozone and time as variability factors $\left({ }^{* *} p \leq 0.001\right)$. For each compound $(\mathbf{A}-\mathbf{C})$, different lowercase letters $(\mathrm{a}-\mathrm{d})$ indicate significant differences among means, according to the Tukey's HSD post-hoc test $(p \leq 0.05)$. The dashed bar indicates the ozone treatment (i.e., $5 \mathrm{~h}$ ). FW $=$ fresh weight. 


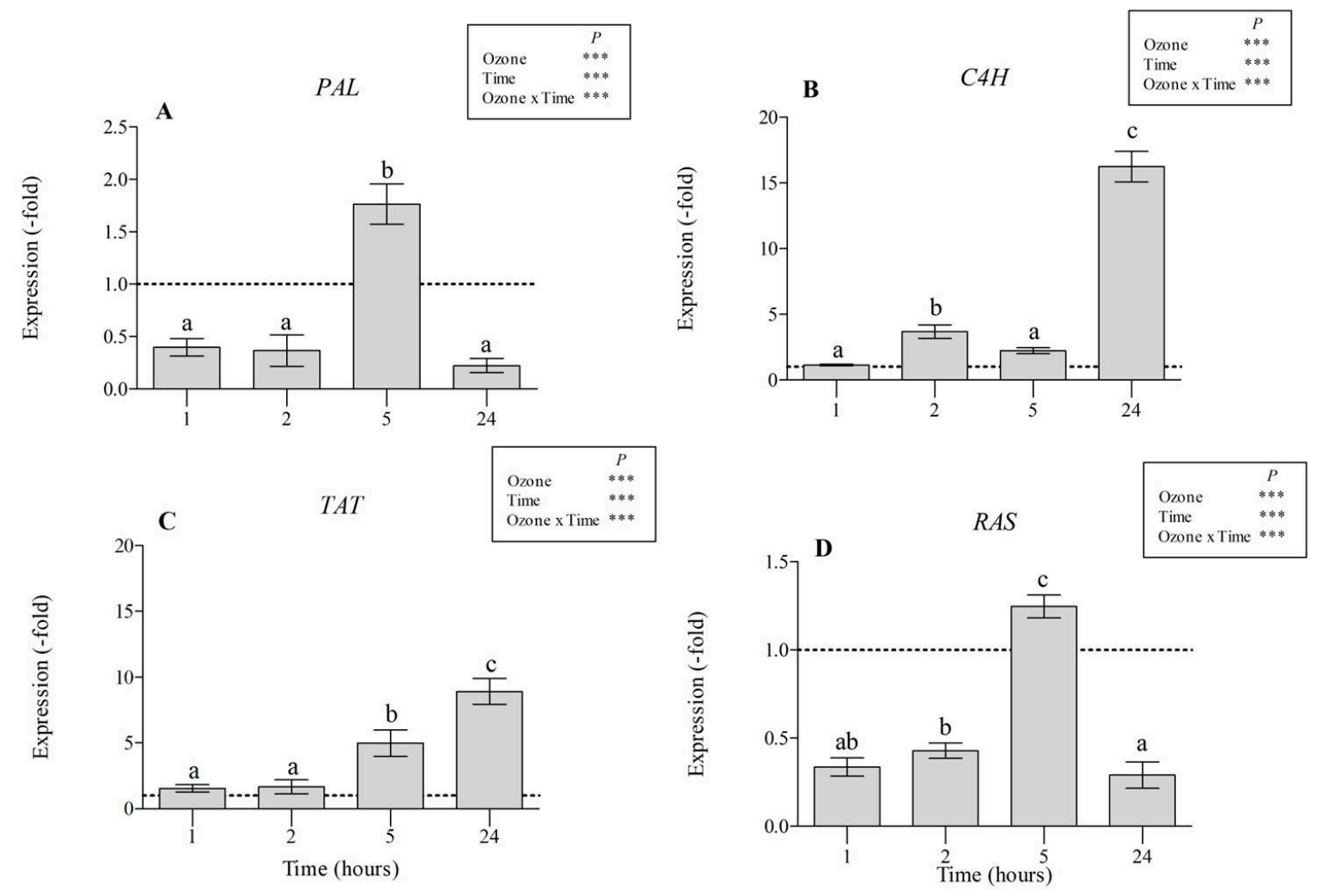

Figure 5. Expression levels of phenylalanine ammonia-lyase (PAL; (A)), cinnamic acid 4-hydroxylase $(\mathrm{C} 4 \mathrm{H} ;(\mathbf{B}))$, tyrosine aminotransferase (TAT; $(\mathbf{C}))$, and rosmarinic acid synthase (RAS; (D)) genes in leaves of Salvia officinalis exposed to ozone (120 ppb, $5 \mathrm{~h})$. Gene expression in plants maintained under filtered air (controls) was set to the value 1.0 (dashed line). Data are shown as mean \pm standard deviation $(n=3)$. Measurements were carried out at $1,2,5$, and $24 \mathrm{~h}$ from the beginning of exposure. Different letters indicate significant differences $(p \leq 0.05)$. Boxes show the results of a full factorial two-way ANOVA with ozone and time as variability factors $(* * * \leq 0.001)$. For each compound (A-C), different lowercase letters $(\mathrm{a}-\mathrm{c})$ indicate significant differences among means, according to the Tukey's HSD post-hoc test $(p \leq 0.05)$.

\section{Discussion}

In another experiment carried out by our research group [17] and focused on the ecophysiological and antioxidant responses of $\mathrm{S}$. officinalis under a prolonged $\mathrm{O}_{3}$ exposure $(120 \mathrm{ppb}$ for 90 consecutive days, $5 \mathrm{~h} \mathrm{day}^{-1}$ ), treated plants showed leaf yellowing and some disorders of leaf water status starting from 30 days FBE, suggesting that metabolic and cell ultrastructural impairments occurred. However, S. officinalis was able to alleviate the oxidative pressure and to defend itself by non-enzymatic antioxidant mechanisms, including carotenoids and phenols. In particular, we speculated that the reprogramming of metabolism to reroute carbon skeletons towards the synthesis of specialized metabolites represented an essential strategy in plant defence. However, the phenylpropanoid response of S. officinalis to chronic and acute $\mathrm{O}_{3}$ may differ [18]. Therefore, the first question we wanted to address was, "What is the potential role of phenolics (e.g., caffeic acid derivatives) and flavonoids in regulating the responses to a single $\mathrm{O}_{3}$ pulse?"

Among the phenolic compounds, a major part of ROS scavenging activities is due to flavonoids as they show a wide localization in plant organs as well as different cells and cellular compartments. The number and arrangement of their hydroxyl groups attached to ring structures are important [30]. In the present study, we identified only two mono-B-ring-substituted flavonoids, i.e., the flavone apigenin and the flavanol kaempferol, both classified as "poor antioxidants" in comparison with other flavonoids [31]. These compounds showed different $\mathrm{O}_{3}$-induced responses; the apigenin content was 
significantly altered only during the first two hours of the $\mathrm{O}_{3}$ treatment, whereas kaempferol markedly changed starting from $2 \mathrm{~h}$ FBE. These secondary metabolites could be involved (i) in the capture of superoxide anions and reduction of cell membrane peroxidation, as confirmed by the decrease of apigenin and kaempferol observed at 1 and $2 \mathrm{~h}$ FBE, respectively; and (ii) in the regulation of $\mathrm{H}_{2} \mathrm{O}_{2}$ and prevention of hydroxyl radical production for stress signalling, as confirmed by the significant increase of apigenin observed at $2 \mathrm{~h}$ FBE and of kaempferol starting from the end of exposure [30].

Overall, the above-mentioned $\mathrm{O}_{3}$-induced variations of phenolic compounds were quite impressive given their magnitude, variability, and rapidity. However, considerable phenolic variations within few hours of exposure to different stresses were already reported in previous studies (e.g., [9,25,26,32,33]), although the phenolic responses (as well as other regulations) of plants to an $\mathrm{O}_{3}$ pulse remain understudied, at least in comparison with experiments focused on chronic $\mathrm{O}_{3}$ exposures [34,35]. Dramatic and variable phenolic changes reported in the present study, following metabolite-specific trends, were likely owing to the diversion of the investigated metabolites to other phenolic products as a result of specific changes in allocation within the different phenolic groups, as reported by Wellburn and Wellburn [36]. Specifically, flavonoids possess multiple physiological functions such as antioxidants, pathogen defense, insect attraction, rhizobium symbiosis, and auxin transport [37]. Moreover, a popular concept assumes that flavonoids are phytoalexins that can be inducibly synthesized by plants in response to pathogen and/or insect challenges [38]; and a single pulse of $\mathrm{O}_{3}$ is known to mimic a pathological agent by triggering a variety of defense reactions in plants that include the following: (i) rapid and transient increase of apoplastic ROS and (ii) induction of hypersensitive response [39]. Nevertheless, these results show that $S$. officinalis coping with a single $\mathrm{O}_{3}$ pulse was able to modify the phenylpropanoid pathway and likely take advantage of the specific defence functions associated to the array of their specialized metabolites. In particular, phenolics might be essential to regulate antioxidant defence and detoxification responses, either during or after the $\mathrm{O}_{3}$ treatment.

In light of the above, the second question was, "Which enzymes involved in the phenolic pathway are more affected by high $\mathrm{O}_{3}$ levels, and why?" It is known that the biosynthesis of phenolics under stressful conditions is regulated by the altered activities of various key enzymes of phenolic biosynthetic pathways like PAL (which catalyzes the initial step in the biosynthesis of plant phenolics and operates as a key regulatory enzyme in specialized metabolism) [40], PPO (which catalyzes the oxidation of monophenols and/or $o$-diphenols to $o$-quinones) [41], and RAS (which links PAL- and TAT-derived pathways to form RA as end product) [42]. In our study, an early decrease of all enzyme activities was observed during the first hours of treatment, probably due to an $\mathrm{O}_{3}$-induced oxidative damage to several proteins. This phenomenon occurs when the production of ROS exceeds the antioxidant defence mechanisms [43]. Both PAL and PPO activities were also suppressed at $24 \mathrm{~h}$ FBE, suggesting that these enzymes were probably not involved in defence response at the recovery time. Then, given the enhanced performance of RAS observed at the end of treatment and at the recovery time, it is possible to speculate that $S$. officinalis experiencing a single $\mathrm{O}_{3}$ pulse activated distinct pathways with different functions, likely to cope with potential future stress episodes [44]. This could be accompanied by the up- and downregulation of the transcript levels of genes encoding key biosynthetic enzymes in regulation of signal transduction systems and stress responses [4].

The third question was, "Which molecular alterations of gene expression related to the biosynthesis of RA are induced by $\mathrm{O}_{3}$ treatment?" Our results indicate that $P A L, R A S, C 4 H$, and TAT affect RA formation with varying degree and timing. This is in accordance with the study by Wang et al. [45], where 29 genes related to phenolic acid biosynthesis were identified in the genome of S. miltiorrhiza, ten of which are putatively involved in RA biosynthesis. In particular, the RA accumulation observed at $24 \mathrm{~h}$ FBE might be a result of the upregulation at different times of several co-expressed genes involved in RA biosynthesis (PAL and RAS at $5 \mathrm{~h} \mathrm{FBE;} \mathrm{C4H} \mathrm{and} \mathrm{TAT} \mathrm{throughout} \mathrm{the} \mathrm{entire} \mathrm{experiment).}$ In particular, the determination of transcript levels of genes encoding enzymes involved in RA biosynthesis by quantitative RT-PCR reflected the sequence of events taking place during and after the $\mathrm{O}_{3}$ treatment of $S$. officinalis. Following the decrease of both RA content, and PAL and RAS 
activities observed during $\mathrm{O}_{3}$ treatment, $P A L$ and $R A S$ genes were rapidly induced, as confirmed by upregulation of their expression at $5 \mathrm{~h}$ FBE. This regulation consequently resulted in the increase of RAS activity observed starting from the end of $\mathrm{O}_{3}$ treatment, as well as of RA content at $24 \mathrm{~h}$ FBE. As reported by Ejtahed et al. [46], no positive relation was observed between the expression intensity of $P A L$ and the accumulation of RA, indicating that $P A L$ is not the rate-determining step in RA biosynthesis and other unknown factors might participate in RA synthesis. It is worth noting that $P A L$ genes have been cloned from different plant species where they usually exist in polygenic families, with three to nine members $[47,48]$. To date, we do not know how many PAL members are present in S. officinalis. In addition, an increased expression profile of genes encoding enzymes in the early part of the phenylpropanoid and flavonoid biosynthesis pathway (such as $C 4 H$ ) [49] and in the early section of RA biosynthesis (such as TAT) was observed throughout the whole experiment, suggesting that the mechanisms regulating proteins encoded by these genes were, at least in part, at transcriptional level, according to Gottardini et al. [50]. Song and Li [51] suggested that four genes (PAL, C4H, 4CL, and HPPR) may serve as key genes in the regulation of rosmarinic acid accumulation in S. miltiorrhiza, while TAT may play an important role in regulating the content of salvianolic acid $\mathrm{B}$. It is known that TAT is the first enzyme in the tyrosine-derived branch of RA biosynthesis. Its product, 4-hydroxyphenylpyruvic acid, serves as a precursor for homogentisic acid (catalyzed by hydroxyphenylpyruvate dioxygenase, HPPD), which is important for the formation of plastoquinones and tocopherols [52], as well as substrate for hydroxyphenylpyruvate reductase, the enzyme forming 4-hydroxyphenyllactic acid as precursor for RA [42]. Therefore, TAT activity is also required for the formation of other antioxidative compounds such as tocopherols [53].

\section{Conclusions}

In conclusion, S. officinalis faced the $\mathrm{O}_{3}$ pulse by regulating the activation and the timing of the phenolic biosynthetic route. Ozone-induced changes of phenylpropanoid profile were quite impressive in terms of magnitude, variability, and rapidity. This regulation was likely an integrated defence mechanism, although further research would be needed to reinforce the observed phenolic and flavonoid arrangements and confirm their involvement in coping $\mathrm{O}_{3}$ stress. Specifically, the performance of RAS was enhanced, accompanied by the upregulation of the transcript levels of genes encoding key biosynthetic enzymes, like RAS (only at $5 \mathrm{~h} \mathrm{FBE),} \mathrm{TAT,} \mathrm{and} C 4 H$. In this way, stressed plants were probably equipped with an additional 'secondary' antioxidant system capable of controlling the cascades of uncontrolled oxidation mechanisms and protecting plant cells from $\mathrm{O}_{3}$-induced oxidative damage. Further studies may be useful to investigate other genes coding for enzymes in branching points (and not directly involved in RA biosynthesis), where the flux might be redirected from the RA pathway (e.g., CHS) [54], in order to evaluate their role in RA accumulation.

Author Contributions: Conceptualization, E.P., C.N., and M.P.; methodology, software, validation, investigation, and formal analysis, A.M. and R.D.; resources, E.P., C.N., G.L., and M.P.; data curation, E.P. and L.C.; writing-original draft preparation and review and editing, E.P. and L.C.; supervision, E.P., C.N., G.L., and M.P. All authors have read and agreed to the published version of the manuscript.

Funding: This research received no external funding.

Acknowledgments: We gratefully acknowledge Andrea Parrini for technical support for the fumigation facilities and Simona Ciangherotti for greenhouse activities.

Conflicts of Interest: The authors declare no conflict of interest.

\section{References}

1. Mittler, R. Abiotic stress, the field environment and stress combination. Trends Plant Sci. 2006, 11, 15-19. [CrossRef] [PubMed]

2. Soares, C.; Carvalho, M.E.; Azevedo, R.A.; Fidalgo, F. Plants facing oxidative challenges-A little help from the antioxidant networks. Environ. Exp. Bot. 2019, 161, 4-25. [CrossRef] 
3. Huang, H.; Ullah, F.; Zhou, D.-X.; Yi, M.; Zhao, Y. Mechanisms of ROS regulation of plant development and stress responses. Front. Plant Sci. 2019, 10, 800. [CrossRef] [PubMed]

4. Isah, T. Stress and defense responses in plant secondary metabolites production. Biol. Res. 2019, 52, 39. [CrossRef] [PubMed]

5. Sharma, A.; Shahzad, B.; Rehman, A.; Bhardwaj, R.; Landi, M.; Zheng, B. Response of phenylpropanoid pathway and the role of polyphenols in plants under abiotic stress. Molecules 2019, 24, 2452. [CrossRef]

6. Cheynier, V.; Comte, G.; Davies, K.M.; Lattanzio, V.; Martens, S. Plant phenolics: Recent advances on their biosynthesis, genetics, and ecophysiology. Plant Physiol. Biochem. 2013, 72, 1-20. [CrossRef]

7. Rice-Evans, C.A.; Miller, N.J.; Paganga, G. Structure-antioxidant activity relationships of flavonoids and phenolic acids. Free Radic. Biol. Med. 1996, 20, 933-956. [CrossRef]

8. Olszowy, M. What is responsible for antioxidant properties of polyphenolic compounds from plants? Plant Physiol. Biochem. 2019, 14, 135-143. [CrossRef]

9. Döring, A.S.; Pellegrini, E.; Della Bartola, M.; Nali, C.; Lorenzini, G.; Petersen, M. How do background ozone concentrations affect the biosynthesis of rosmarinic acid in Melissa officinalis? J. Plant Physiol. 2014, 171, $35-41$. [CrossRef]

10. Vergine, M.; Nicolì, F.; Negro, C.; Luvisi, A.; Nutricati, E.; Accogli, R.A.; Sabella, E.; Miceli, A. Phytochemical profiles and antioxidant activity of Salvia species from Southern Italy. Rec. Nat. Prod. 2019, 13, 205-215. [CrossRef]

11. Lu, Y.; Foo, L.Y. Polyphenolics of Salvia-A review. Phytochemistry 2002, 59, 117-140. [CrossRef]

12. Agati, G.; Azzarello, E.; Pollastri, S.; Tattini, M. Flavonoids as antioxidants in plants: Location and functional significance. Plant Sci. 2012, 196, 67-76. [CrossRef] [PubMed]

13. Kumar, S.; Pandey, A.K. Chemistry and biological activities of flavonoids: An overview. Sci. World J. 2013. [CrossRef] [PubMed]

14. Lorenzini, G.; Nali, C. Ozone and plant life: The Italian state-of-the-art. Environ. Sci. Pollut. Res. 2018, 25, 8069-8073. [CrossRef]

15. European Environment Agency (EEA). Air Quality in Europe. EEA Report 10/2019. Available online: https://www.eea.europa.eu/publications/air-quality-in-europe-2019 (accessed on 21 October 2019).

16. Cotrozzi, L.; Pellegrini, E.; Nali, C.; Lorenzini, G. Climate change, ozone and plant life. Agrochimica 2019, 181-188.

17. Pellegrini, E.; Francini, A.; Nali, C.; Lorenzini, G. Ecophysiological and antioxidant traits of Salvia officinalis under ozone stress. Environ. Sci. Pollut. Res. 2015, 22, 13083-13093. [CrossRef]

18. Emberson, L.D.; Pleijel, H.; Ainsworth, E.A.; van den Berg, M.; Ren, W.; Osborne, S.; Mills, G.; Pandey, D.; Dentener, F.; Büker, P.; et al. Ozone effects on crops and consideration in crop models. Eur. J. Agron. 2018, 100, 19-34. [CrossRef]

19. Marchica, A.; Lorè, S.; Cotrozzi, L.; Lorenzini, G.; Nali, C.; Pellegrini, E.; Remorini, D. Early detection of sage (Salvia officinalis L.) responses to ozone using reflectance spectroscopy. Plants 2019, 8, 346. [CrossRef]

20. Fini, A.; Guidi, L.; Ferrini, F.; Brunetti, C.; Di Ferdinando, M.; Biricolti, S.; Pollastri, S.; Calamai, L.; Tattini, M. Drought stress has contrasting effects on antioxidant enzymes activity and phenylpropanoid biosynthesis in Fraxinus ornus leaves: An excess light stress affair? J. Plant Physiol. 2012, 169, 929-939. [CrossRef]

21. Ragusa, A.; Centonze, C.; Grasso, M.E.; Latronico, M.F.; Mastrangelo, P.F.; Sparascio, F.; Maffia, M. HPLC analysis of phenols in Negroamaro and Primitivo red wines from Salento. Foods 2019, 8, 45. [CrossRef]

22. Leuschner, M. Untersuchungen zu Phenoloxidasen aus Zellkulturen von Lycopersicum esculentum Mill. Doctoral Thesis, Philipps-Universität Marburg, Marburg, Germany, 2002.

23. Berger, A.; Meinhard, J.; Petersen, M. Rosmarinic acid synthase is a new member of the superfamily of BAHD acyltransferases. Planta 2006, 224, 1503-1510. [CrossRef] [PubMed]

24. Pfaffl, M.W. A new mathematical model for relative quantification in real-time RT-PCR. Nucleic Acids Res. 2001, 29, 2002-20007. [CrossRef]

25. Sgarbi, E.; Medeghini Bonatti, P.; Baroni Fornasiero, R.; Lins, A. Differential sensitivity to ozone in two selected cell lines from grape leaf. J. Plant Physiol. 1999, 154, 119-126. [CrossRef]

26. Pasqualini, S.; Piccioni, C.; Reale, L.; Ederli, L.; Della Torre, G.; Ferranti, F. Ozone-induced cell death in tobacco cultivar Bel W3 plants. The role of programmed cell death in lesion formation. Plant Physiol. 2003, 133, 1122-1134. [CrossRef] 
27. Pellegrini, E.; Hoshika, Y.; Dusart, N.; Cotrozzi, L.; Gérard, J.; Nali, C.; Vaultier, M.N.; Jolivet, Y.; Lorenzini, G.; Paoletti, E. Antioxidative responses of three oak species under ozone and water stress conditions. Sci. Total Environ. 2019, 647, 390-399. [CrossRef] [PubMed]

28. Larson, R.A. The antioxidants of higher plants. Phytochemistry 1988, 27, 969-978. [CrossRef]

29. Widhalm, J.R.; Dudareva, N. A familiar ring to it: Biosynthesis of plant benzoic acids. Mol. Plant 2015, 8, 83-97. [CrossRef]

30. Gill, S.S.; Tuteja, N. Reactive oxygen species and antioxidant machinery in abiotic stress tolerance in crop plants. Plant Physiol. Biochem. 2010, 48, 909-930. [CrossRef]

31. Agati, G.; Tattini, M. Multiple functional roles of flavonoids in photoprotection. New Phytol. 2010, 186, 786-793. [CrossRef]

32. Mosadegh, H.; Trivellini, A.; Ferrante, A.; Lucchesini, M.; Vernieri, P.; Mensuali, A. Applications of UV-B lighting to enhance phenolic accumulation of sweet basil. Sci. Hortic. 2018, 229, 107-116. [CrossRef]

33. Yoshikawa, M.; Luo, W.; Tanaka, G.; Konishi, Y.; Matsuura, H.; Takahashi, K. Wounding stress induces phenylalanine ammonia lyase, leading to the accumulation of phenylpropanoids in the model liveworth Marchantia polymorpha. Phytochemistry 2018, 155, 30-36. [CrossRef]

34. Grulke, N.E.; Paoletti, E.; Heat, R.L. Chronic vs. short-term acute $\mathrm{O}_{3}$ exposure effects on nocturnal transpiration in two Californian Oaks. Sci. World J. 2007, 7, 134-140. [CrossRef]

35. Cotrozzi, L. The effects of tropospheric ozone on oaks: A global meta analysis. Sci. Total Environ. 2020, 756, 143795. [CrossRef]

36. Wellburn, F.A.M.; Wellburn, A.R. Variable patterns of antioxidant protection but similar ethene emission differences in several ozone-sensitive and ozone-tolerant plant selections. Plant Cell Environ. 1996, 19, 754-760. [CrossRef]

37. Agati, G.; Brunetti, C.; Fini, A.; Gori, A.; Guidi, L.; Landi, M.; Sebastiani, F.; Tattini, M. Are flavonoids effective antioxidants in plants? Twenty years of our investigation. Antioxidant 2020, 9, 1098. [CrossRef]

38. Ahuja, L.; Kissen, R.; Bones, A.M. Phytoalexins in defence against pathogens. Trends Plant Sci. 2012, 17, 73-90. [CrossRef]

39. Kangasjarvi, J.; Jaspers, P.; Kollist, H. Signalling and cell death in ozone-exposed plants. Plant Cell Environ. 2005, 28, 1021-1035. [CrossRef]

40. Hahlbrock, K.; Scheel, D. Physiology and molecular biology of phenylpropanoid metabolism. Annu. Rev. Plant Biol. 1989, 40, 347-369. [CrossRef]

41. Taranto, F.; Pasqualone, A.; Mangini, G.; Tripodi, P.; Miazzi, M.M.; Pavan, S.; Montemurro, C. Polyphenol oxidases in crops: Biochemical, physiological and genetic aspects. Int. J. Mol. Sci. 2017, 18, 337. [CrossRef]

42. Petersen, M.; Alfermann, A.W. Two new enzymes of rosmarinic acid biosynthesis from cell cultures of Coleus blumei: Hydroxyphenylpyruvate reductase and rosmarinic acid synthase. Z. Nat. C 1988, 43, 501-504. [CrossRef]

43. Rao, M.V.; Hale, B.A.; Ormrod, D.P. Amelioration of ozone-induced oxidative damage in wheat plants grown under high carbon dioxide. Plant Physiol. 1995, 109, 421-432. [CrossRef]

44. Zhao, D.L.C.; Verpoorte, R. Elicitor signal transduction leading to production of plant secondary metabolites. Biotechnol. Adv. 2005, 23, 283-333. [CrossRef]

45. Wang, B.; Sun, W.; Li, Q.; Li, Y.; Luo, H.; Song, J.; Sun, C.; Qian, J.; Zhu, Y.; Hayward, A.; et al. Genome-wide identification of phenolic acid biosynthetic genes in Salvia miltiorrhiza. Planta 2015, 241, 711-725. [CrossRef]

46. Ejtahed, R.; Radjabian, T.; Hoseini Tafreshi, S.A. Expression analysis of phenylalanine ammonia lyase gene and rosmarinic acid production in Salvia officinalis and Salvia virgata shoots under salicylic acid elicitation. Appl. Biochem. Biotechnol. 2015, 176, 1846-1858. [CrossRef]

47. Raes, J.; Rohde, A.; Christensen, J.H.; Van de Peer, Y.; Boerjan, W. Genome-wide characterization of the lignification toolbox in Arabidopsis. Plant Physiol. 2003, 133, 1051-1071. [CrossRef]

48. Li, G.; Wang, H.; Cheng, X.; Su, X.; Zhao, Y.; Jaing, T.; Jin, Q.; Lin, Y.; Cai, Y. Comparative genomic analysis of the PAL genes in five Rosaceae species and functional identification of Chinese white pear. Peer J. 2019, 7 , e8064. [CrossRef]

49. Liu, X.Y.; Yu, H.N.; Gao, S.; Wu, Y.F.; Cheng, A.X.; Lou, H.X. The isolation and functional characterization of three liverwort genes encoding cinnamate 4-hydroxylase. Plant Physiol. Biochem. 2014, 117, 42-50. [CrossRef] 
50. Gottardini, E.; Cristofori, A.; Pellegrini, E.; La Porta, N.; Nali, C.; Baldi, P.; Sablok, G. Suppression subtractive hybridization and NGS reveal differential transcriptome expression profiles in wayfaring tree (Viburnum lantana L.) treated with ozone. Front. Plant Sci. 2016, 7, 713. [CrossRef]

51. Song, Z.; Li, X. Expression profiles of rosmarinic acid biosynthesis genes in two Salvia miltiorrhiza lines with differing water-soluble phenolic contents. Ind. Crops Prod. 2015, 71, 24-30. [CrossRef]

52. Kim, K.H.; Janiak, V.; Petersen, M. Purification, cloning and functional expression of hydroxyphenylpyruvate reductase involved in rosmarinic acid biosynthesis in cell cultures of Coleus blumei. Plant Mol. Biol. 2004, 54, 311-323. [CrossRef]

53. Wang, M.; Toda, K.; Block, A.; Maeda, H.A. TAT1 and TAT2 tyrosine aminotransferases have both distinct and shared functions in tyrosine metabolism and degradation in Arabidopsis thaliana. J. Biol. Chem. 2019, 294, 3563-3576. [CrossRef] [PubMed]

54. Trócsányi, E.; György, Z.; Zámboriné-Németh, É. New insights into rosmarinic acid biosynthesis based on molecular studies. Curr. Plant Biol. 2020, 23, 100162. [CrossRef]

Publisher's Note: MDPI stays neutral with regard to jurisdictional claims in published maps and institutional affiliations.

(C) 2020 by the authors. Licensee MDPI, Basel, Switzerland. This article is an open access article distributed under the terms and conditions of the Creative Commons Attribution (CC BY) license (http://creativecommons.org/licenses/by/4.0/). 